\title{
Relationship between Health Literacy and Health- Promoting Behaviors among Teen Pregnant Mothers
}

\author{
ARIESE VINCENT A. BARCA, BSN \\ REINLYNNE D. BAJAR, BSN, RN \\ AMANDA L. CANIEZO, BSN \\ MONIQUE LOUISE DIZON, BSN \\ CHRISTIAN JAY S. ORTE, PhD, RN, RM \\ https://orcid.org/0000-0002-7230-9491
}

Systems Plus College Foundation, Angeles City, Philippines

Corresponding author's email: jay_serafica19@yahoo.com

\section{Abstract}

Background: Teenagers who became pregnant face many pregnancy difficulties as they are less likely to have enough physical development to withstand a healthy pregnancy or to give birth. Thus, health literacy and the promotion of healthy behavior among pregnant mothers are of paramount importance. This study is aimed to assess the relationship between health literacy and healthpromoting behaviors among the selected teen pregnant mothers in attaining maternal health.

Methods: Descriptive-correlational design was employed in this study. A total of 46 respondents participated in the study through a purposive sampling technique. The research instruments used were the Adolescent Health Promotion Scale and Comprehensive Short-form Health Literacy Survey Tool for Patients in General. Frequency, percentage, descriptive mean, and Spearman Rank Correlation were used to analyze the data gathered.

Results: Results showed that teen pregnant mothers have high levels of health literacy $(n=2.16)$ but with low levels of health-promoting behavior $(n=3.45)$. Lastly, it was found out these variables were statistically non-significant $(r s(47)=-.127, p=0.393$ ) to each other.

Conclusion: The study found out that there is no significant relationship between health literacy and health-promoting behaviors among teen pregnant mothers. 
Keywords: Health literacy, health-promoting behaviors, maternal health, teen pregnant mothers

\section{Introduction}

The World Health Organization (WHO) defined adolescence as those aged 10 to 19, and youth as those between 15 and 24 years old. Young people are terms that cover both age groups (WHO, 2010). Teenagers who become pregnant face many pregnancy difficulties like the other women related to issues of pregnancy. However, there are additional concerns for those 15 years of age as they are less likely to have attained sufficient physical development to withstand a healthy pregnancy or to give birth (WHO, 2010). As a pregnant mother, health literacy is an important aspect in order to attain maternal health and wellness (Ghanbari, Majlessi, Ghaffari, \& Mahmoodi-Majdabadi, 2012; Viboonwatthanakitt, Pancharean \& Tipalonkot, 2007). Maternal health literacy is defined as the cognitive and social skills determining the ability to get access to, understand, and use the information to promote mothers' health and that of their children. Maternal health literacy is important because antenatal care is the first exposure of many women to the healthcare system (Ghanbari et al., 2012). Promoting healthy behavior among pregnant mothers, on one hand, aims to encourage the development of healthy adult lifestyles and thereby reduce the risk of morbidity and mortality (Walker \& Townsend, 1999). Teenagers are acknowledged to be at high risk in the following: 1) smoking, 2) teenage pregnancy, and 3) drug and alcohol use (Walker \& Townsend, 1999). Additionally, the recognition of high levels of psychological distress is a cause for serious concern about teenage health (Walker \& Townsend, 1999). Even there are studies regarding health literacy and healthpromoting behaviors, seem to primarily focus on individual assessment of these variables. This study aimed to assess the relationship between health literacy and health-promoting behaviors among the selected teen pregnant mothers in attaining maternal health.

\section{Methods}

\section{Research Design}

Descriptive-correlational design was used in this study to determine the relationship healthpromoting behaviors of pregnant mothers with their health literacy.

\section{Population and Sampling Technique}

The $G$ power 3.1.9.4 software was used to identify the total population needed for the study. It yielded 42 sample size with alpha error of 0.05 with a 0.95 confidence and an actual power of 0.9545279. A total of 46 respondents participated in the study via purposive sampling (Polit \& Beck, 2008; Burns \& Groove, 2011) with the following criteria (1) A teenage pregnant mother (2) resides at Systems Plus College Foundation-College of Nursing adopted community, (3) regardless of trimester 
of pregnancy, (4) regardless of her gravida, (5) 13-19 years of age, and (6) willing to participate. The context of the study was conducted in one of the resettlement areas in Pampanga, Philippines where majority of people are indigent and has poor socioeconomic status. In addition, this area has limitation in their access to health care.

\section{Research Instruments}

The study utilized two questionnaires: 1) Adolescent Health Promotion Scale and 2) Comprehensive Short-form Health Literacy Survey Tool. The Adolescent Health Promotion Scale developed by Tomás, Queirós, and Ferreira (2015) with a Cronbach Alpha results of 0.932 . This instrument contains 12 questions under a 4-point Likert scale wherein the score of 4 means very difficult and score of 1 means very easy. On the other hand, Comprehensive Short-form Health Literacy Survey Tool for Patients in General developed by Huang et al. (2017) with a Cronbach Alpha result of 0.87 . This contains 40 questions with 5-points Likert scale in which 5 means always implemented (81-100\%) and 1 means never implemented (1-10\%). Further, permissions were secured from the authors. Since the instruments were generally made for general population or in various groups of samples in relation to health promoting behaviors and health literacy, likewise, it is applicable also for pregnant mothers. In addition, these instruments had undergone translation process in English and Filipino using backward and forward translation twice and were validated by experienced Filipino instructors teaching in colleges and universities. Moreover, pilot testing was made in one of the communities of Pampanga which is not under the context of the study to assess its reliability before the data collection was made. It yielded a Cronbach's alpha result of 0.86 (Adolescent Health Promotion Scale) and 0.91 (Comprehensive Short-form Health Literacy Survey Tool) for both translated instruments respectively.

\section{Ethical Considerations}

The ethics review was approved by Our Lady of Fatima University (OLFU) Institutional Ethics Review Committee (IERC) in order to assess the ethical considerations regarding human participants with a protocol number of 2018-IERC1-20250V2. In addition, a letter of permission was secured from the Barangay Captain as well as the rural health midwife of as part of our courtesy call before the conduction of the study to the target area. Consent was given by the participants prior to data collection. For participants who are less than 18 years old, an assent form was provided which is proof that they are willing to participate. Further, permission was sought also from their parents. It is also included in the instructions to withdraw during the conduction of the study anytime without any penalty. Likewise, the utmost confidentiality and anonymity were exhibited in this study by not revealing the names of the participants rather these were replaced by pseudonyms. All of the collected survey questionnaires were stored in a locked cabinet where we only have the access. We tallied and validated the tabulation twice before it was sent to the statistician for its analysis. Questionnaires were destroyed using a paper shredder and were disposed of properly 6 months after the full paper made as part of our research protocol. 


\section{Data Analysis}

For the data analysis, we used the Statistical Package for Social Sciences version 21 with the following: Frequency, percentage, descriptive mean, and Spearman's Rank Correlations.

\section{Results}

Table 1 presents the demographic profile of the respondents. As shown, forty-seven (47) adolescents participated in the study. Most of the participants belong to the age group of 18 years old $(n=13,28 \%)$. Most of them are under high school undergraduate $(n=17,36 \%)$ and unemployed $(n=39,83 \%)$. A greater proportion of the participants are currently in their 3rd trimester $(n=39,83 \%)$.

Table 1. Demographic Profile of the Participants

\begin{tabular}{ccclcc}
\hline Characteristics & $\mathbf{n}$ & Percentage & \multicolumn{1}{c}{ Characteristics } & $\mathbf{n}$ & Percentage \\
\hline Age in Years & & & Educational Attainment & & \\
14 & 3 & 6 & Elementary Undergraduate & 8 & 17 \\
15 & 2 & 4 & Elementary Graduate & 5 & 11 \\
16 & 11 & 23 & High school Undergraduate & 17 & 36 \\
17 & 12 & 26 & High school Graduate & 5 & 11 \\
18 & 13 & 28 & Senior High school & 9 & 19 \\
19 & 6 & 13 & College Undergraduate & 3 & 6 \\
& & & College Graduate & 0 & 0 \\
Terms of Pregnancy & & & Employment Status & & \\
$1^{\text {st trimester }}$ & 1 & 2 & Unemployed & 39 & 83 \\
$2^{\text {nd }}$ trimester & 7 & 15 & Self-employed & 2 & 4 \\
$3^{\text {rd }}$ trimester & 39 & 83 & Employed & 6 & 13 \\
\hline
\end{tabular}

Table 2 presents the self-evaluated health literacy level of the teenage pregnant mothers. Most of the participants got an overall mean score of 2.16 (Fairly Easy) on Health literacy.

Table 2. Self-Evaluated Health Literacy of the Participants

\begin{tabular}{|c|c|c|c|c|c|}
\hline INDICATORS & Mean & SD & $\operatorname{Max}$ & Min & Description \\
\hline $\begin{array}{l}\text { Find information on treatments of illnesses that } \\
\text { concern you? }\end{array}$ & 2.36 & .705 & 4 & 1 & Fairly Easy \\
\hline $\begin{array}{l}\text { Understand that leaflets that come with your } \\
\text { medicine? }\end{array}$ & 2.45 & .775 & 4 & 1 & Fairly Easy \\
\hline $\begin{array}{l}\text { Judge the advantages and disadvantages of } \\
\text { different treatment options? }\end{array}$ & 2.51 & .748 & 4 & 1 & Fairly Easy \\
\hline Call an ambulance in an emergency & 2.28 & 1.015 & 4 & 1 & Fairly Easy \\
\hline $\begin{array}{l}\text { Find information on how to manage mental } \\
\text { health problems like stress or depression? }\end{array}$ & 2.60 & .851 & 4 & 1 & Fairly Easy \\
\hline
\end{tabular}




\begin{tabular}{|c|c|c|c|c|c|}
\hline INDICATORS & Mean & SD & Max & Min & Description \\
\hline $\begin{array}{l}\text { Understand why you need health screenings } \\
\text { (such as breast exam, blood sugar test, blood } \\
\text { pressure)? }\end{array}$ & 2.47 & .929 & 4 & 1 & Fairly Easy \\
\hline Judge which vaccinations you may need? & 2.00 & .933 & 4 & 1 & Fairly Easy \\
\hline $\begin{array}{l}\text { Decide how you can protect yourself from illness } \\
\text { based on advice from family and friends? }\end{array}$ & 2.17 & .868 & 4 & 1 & Fairly Easy \\
\hline $\begin{array}{l}\text { Find out about activities (such as mediation, } \\
\text { exercise, walking, pilates etc.) that are good for } \\
\text { your mental well-being? }\end{array}$ & 2.00 & .780 & 4 & 1 & Fairly Easy \\
\hline $\begin{array}{l}\text { Understand information in the media (such as } \\
\text { internet, newpaper, magazines) on how to get } \\
\text { healthier? }\end{array}$ & 2.02 & .897 & 4 & 1 & Fairly Easy \\
\hline $\begin{array}{l}\text { Judge which everyday behavior (such as } \\
\text { drinking and eating habits, exercise etc.) is } \\
\text { related to your health }\end{array}$ & 1.79 & .750 & 3 & 1 & Very Easy \\
\hline $\begin{array}{l}\text { Join a sports club or exercise class if you want } \\
\text { to? }\end{array}$ & 1.74 & .765 & 3 & 1 & Very Easy \\
\hline Overall & 2.16 & 0.83 & 3.83 & 1 & Fairly Easy \\
\hline
\end{tabular}

Table 3 depicts the health-promoting behavior of teenage pregnant mothers. As glean on the table, most of the participants got an overall mean score of 3.45 (Sometimes) on Health behavior.

Table 3. Self-evaluated Health Promoting Behavior of the Participants

\begin{tabular}{|c|c|c|c|c|c|}
\hline INDICATORS & Mean & SD & Max & Min & Description \\
\hline $\begin{array}{l}\text { As three meals a day (breakfast, lunch and } \\
\text { dinner). }\end{array}$ & 4.40 & .948 & 5 & 2 & A lot of times \\
\hline Choose foods without too much oil. & 2.83 & .842 & 5 & 1 & Few \\
\hline $\begin{array}{l}\text { I include dietary fiber in my diet (eg fruits or } \\
\text { vegetables). }\end{array}$ & 3.38 & 1.190 & 5 & 1 & Sometimes \\
\hline $\begin{array}{l}\text { Drink at least } 1.5 \mathrm{~L} \text { of water per day (or } 6-8 \\
\text { glasses). }\end{array}$ & 3.81 & 1.154 & 5 & 1 & Sometimes \\
\hline $\begin{array}{l}\text { I include five food groups at each meal (eg } \\
\text { bread, meat or fish, dairy products, fruit and } \\
\text { vegetables) }\end{array}$ & 3.89 & .961 & 5 & 1 & Sometimes \\
\hline I eat breakfast every day. & 3.91 & 1.176 & 5 & 1 & Sometimes \\
\hline I share and tell about my feelings with others. & 3.21 & 1.284 & 5 & 1 & Sometimes \\
\hline I care about other people. & 3.72 & 1.192 & 5 & 1 & Sometimes \\
\hline I talk about my concerns with others. & 3.11 & .787 & 4 & 1 & Sometimes \\
\hline Every day I struggle to smile or laugh. & 3.38 & .968 & 5 & 1 & Sometimes \\
\hline I like to keep in touch with my family. & 4.43 & .853 & 5 & 3 & A lot of times \\
\hline I make an effort to have good friendships. & 4.11 & 1.184 & 5 & 1 & A lot of times \\
\hline I talk about my problems with others. & 2.79 & .858 & 4 & 1 & Few \\
\hline $\begin{array}{l}\text { When shopping, I read labels on food } \\
\text { packaging. }\end{array}$ & 3.13 & 1.312 & 5 & 1 & Sometimes \\
\hline I watch over my weight. & 2.81 & 1.362 & 5 & 1 & Few \\
\hline
\end{tabular}




\begin{tabular}{|c|c|c|c|c|c|}
\hline INDICATORS & Mean & SD & Max & Min & Description \\
\hline $\begin{array}{l}\text { Discuss my health concerns with a doctor or } \\
\text { nurse. }\end{array}$ & 3.02 & 1.260 & 5 & 1 & Sometimes \\
\hline I watch my body at least once a month. & 3.11 & 1.306 & 5 & 1 & Sometimes \\
\hline $\begin{array}{l}\text { I brush my teeth at least twice a day and use } \\
\text { dental floss daily. }\end{array}$ & 3.68 & 1.431 & 5 & 1 & Sometimes \\
\hline I wash my hands before meals. & 4.15 & 1.318 & 5 & 1 & A lot of times \\
\hline I read health information. & 3.57 & 1.638 & 5 & 1 & Sometimes \\
\hline $\begin{array}{l}\text { I make an effort to choose foods without } \\
\text { preservatives. }\end{array}$ & 3.34 & 1.006 & 5 & 1 & Sometimes \\
\hline I make an effort to like myself. & 3.98 & 1.359 & 5 & 1 & Sometimes \\
\hline I make an effort to feel happy and content. & 3.87 & 1.172 & 5 & 1 & Sometimes \\
\hline Normally, I think positively & 3.53 & .929 & 5 & 1 & Sometimes \\
\hline $\begin{array}{l}\text { I make an effort to understand and accept my } \\
\text { strengths and weaknesses. }\end{array}$ & 3.30 & 1.267 & 5 & 1 & Sometimes \\
\hline I make an effort to correct my faults. & 4.09 & 1.158 & 5 & 1 & A lot of times \\
\hline $\begin{array}{l}\text { I make an effort to know what is important to } \\
\text { me. }\end{array}$ & 3.98 & .921 & 5 & 2 & Sometimes \\
\hline $\begin{array}{l}\text { I make an effort to feel interested and } \\
\text { challenged every day. }\end{array}$ & 3.34 & 1.147 & 5 & 1 & Sometimes \\
\hline $\begin{array}{l}\text { I make an effort to believe that my life has a } \\
\text { purpose. }\end{array}$ & 3.47 & 1.080 & 5 & 1 & Sometimes \\
\hline I stretch every day. & 2.87 & 1.191 & 5 & 1 & Few \\
\hline $\begin{array}{l}\text { I exercise vigorously for } 30 \text { minutes at least } 3 \\
\text { times a week. }\end{array}$ & 2.51 & .975 & 5 & 1 & Few \\
\hline $\begin{array}{l}\text { I participate in Physical Education classes at } \\
\text { school weekly. }\end{array}$ & 2.62 & 1.208 & 5 & 1 & Few \\
\hline I warm up before vigorous exercise. & 2.62 & 1.609 & 5 & 1 & Few \\
\hline $\begin{array}{l}\text { I make an effort to be upright when I am } \\
\text { standing or sitting. }\end{array}$ & 3.87 & 1.154 & 5 & 1 & Sometimes \\
\hline $\begin{array}{l}\text { I make an effort to spend some time relaxing } \\
\text { every day. }\end{array}$ & 4.21 & .931 & 5 & 3 & A lot of times \\
\hline $\begin{array}{l}\text { I make an effort to determine the source of my } \\
\text { stress. }\end{array}$ & 2.89 & 1.238 & 5 & 1 & Few \\
\hline I make an effort to observe my mood swings. & 3.32 & 1.065 & 5 & 1 & Sometimes \\
\hline I sleep 6 to 8 hours every night. & 3.81 & 1.313 & 5 & 1 & Sometimes \\
\hline $\begin{array}{l}\text { I make plans of activities and establish } \\
\text { priorities. }\end{array}$ & 3.49 & 1.266 & 5 & 1 & Sometimes \\
\hline $\begin{array}{l}\text { I try not to lose control when unfair things } \\
\text { happen. }\end{array}$ & 3.32 & 1.086 & 5 & 1 & Sometimes \\
\hline Overall & 3.45 & 1.15 & 4.95 & 1.15 & Sometimes \\
\hline
\end{tabular}

Table 4 depicts the result of Spearman's rank-order correlation regarding health literacy and health-promoting behavior. It reveals that there was a strong, negative correlation between health literacy and health-promoting behavior of teenage pregnant mother, but this was not statistically significant (rs (47) $=-.127, p=.393)$. 
Table 4. Relationship between Health Literacy and Health Promoting Behaviors of Teen Pregnant Mothers

\begin{tabular}{ccc}
\hline R Coefficient & P Value & Interpretation \\
\hline-0.127 & 0.393 & Not Significant
\end{tabular}

${ }^{*} p$ value is significant at 0.05 level

\section{Discussion}

The result of self-evaluated health literacy among teen pregnant mother falls on "fairly easy". This denotes that most of them did not find difficulties in obtaining, processing, and understanding the basic health information and services needed to make appropriate health decisions. This may be linked to the study conducted by Renkert and Nutbeam (2001) wherein they stressed that maternal health literacy is a life skill that mothers use to manage personal, child health and healthcare. It has been defined as the cognitive and social skills that determine the mother's motivation and ability to act on information in ways that improve health. Health literacy on the other definition is a skill that enables the mother to minimize risk, maximize protective factors, and optimize health promotion. In this way, a mother's health literacy forms the foundation for her health and her child's health throughout their lives (Ghanbari et al., 2012). It is essential for the mother because based on a study; low health literacy among pregnant mothers has an impact to their health outcome even with their children (Azugbene, 2017; Ivanova et al., 2017; Lee, 2016). That is why health literacy is important since it prepares the mother for parenthood leading to self-efficacy in taking care of her newborn (Lee, Murry, Ko, \& Kim, 2018).

Based on the result of the study, teenage pregnant mothers understand their condition and they use the information they acquired from healthcare providers to attain health and wellness not only for them but also for their newborn child. It is also noted that self-evaluated health-promoting behaviors of teen pregnant mothers claimed that sometimes they execute these activities. These depict that most of them either may or may not express perceived control over their health and its determinants. These imply that not all of the pregnant mothers even having their follow-up check-up still having problems when it comes to their compliance in maintaining their self-care behavior which can be the cause of being high-risk during their pregnancy period or even upon actual parturition. Health-promoting behaviors among pregnant women likewise is an essential indicator of their health status (Fathnezhad-Kazemi \& Hajian, 2019) especially when the mother achieves her and the baby's desired health outcomes during the period of pregnancy (Fathnezhad-Kazemi, Hajian, EbrahimiMameghani, \& Khabaz Khob, 2017). However, some pregnant mothers are resistant when it comes to their accustomed behaviors (Olander, Smith, \& Darwin, 2018). Therefore, it is highly recommended that nurses and even health care providers are important partners of pregnant women in order to achieve their anticipated health promoting behaviors (Lin et al., 2009).

Lastly, it was found out that health literacy and health-promoting behaviors are Nonsignificant. This implies that health literacy does not affect the teenage pregnant mother's health- 


\section{Conclusion}

The study found out that there was no significant relationship between health literacy and health-promoting behaviors among teen pregnant mothers. Although, most of them know already the consequences of abiding the advocacy of health care providers among pregnant mothers, some of them have not appropriately executed these activities despite the adequacy of their literacy. Therefore, health care providers must continue their diligence in encouraging health promotion as part of the information and education campaign (IEC) among pregnant mothers in order to attain maternal and child health not only during pregnancy but also upon parturition and post-partum periods. Likewise, another study can be conducted since it was done in one resettlement community and the respondents are limited to a small scale only.

\section{References}

Azugbene, E. (2017). Maternal Health Literacy and Maternal and Child Health Outcomes: A Review of the Literature. Annals of Global Health, 83(1), 94. doi: 10.1016/j.aogh.2017.03.208

Burns, N., Grove, S. K. \& Gray, J. (2011). Understanding Nursing Research: Building an Evidence-based practice (5th ed). St. Louis, MO: Saunders/Elsevier.

Fathnezhad Kazemi, A., Hajian, S., Ebrahimi-Mameghani, M. \& Khabaz Khob, M. (2017). The Perspectives of Pregnant Women on Health-Promoting Behaviors: an Integrative Systematic Review. International Journal of Women's Health and Reproduction Sciences, 6(2), 97-105.

doi: 10.15296/ijwhr.2018.17

Fathnezhad-Kazemi, A., \& Hajian, S. (2019). Factors Influencing the Adoption of Health Promoting Behaviors in Overweight Pregnant Women: A Qualitative Study. BMC Pregnancy and Childbirth, 19(1), 43. doi:10.1186/s12884-019-2199-5

Ghanbari S, Majlessi F, Ghaffari M, \& Mahmoodi Majdabadi M. (2012). Evaluation of Health Literacy of Pregnant Women in Urban Health Centers of Shahid Beheshti Medical University. Daneshvar Medicine. 19 (97). 1-12 
Huang, H. L. ,Van Duong, T., Chang, P. W., Yang, S. H., Chen, M. C., Chao, W. T., ... \& Chen, T.(2017). A New Comprehensive Short-form Health Literacy Survey Tool for Patients in General. Asian nursing research, 11(1), 30-35. doi:10.1016/j.anr.2017.02.001

Ivanova, K., Olecka, I., Hruba, K., Ondra, P., Jurickova, L., Hanak, P., \& Horakova, D. (2017). Content of Maternal Health Literacy in the First Year of Motherhood. European Journal of Public Health, 27 (suppl_3). doi: 10.1093/eurpub/ckx186.289

Lee, J. Y. (2016). Maternal Health Literacy among Low-Income Mothers with Infants. (Published Doctoral Dissertation: The University of Texas at Austin, USA), Retrieved from http://hdl.handle.net/2152/40335

Lee, J. Y., Murry, N., Ko, J., \& Kim, M. T. (2018). Exploring the Relationship between Maternal Health Literacy, Parenting Self-Efficacy, and Early Parenting Practices among Low-Income Mothers with Infants. Journal of Health Care for the Poor and Underserved, 29(4), 1455-1471. doi: 10.1353/hpu.2018.0106

Lin, Y. H., Tsai, E., Chan, T.-F., Chou, F.-H., \& Lin, Y.-L. (2009). Health Promoting Lifestyles and Related Factors in Pregnant Women. Chang Gung Medical Journal, 32, 650-661.

Olander, E. K., Smith, D. M., \& Darwin, Z. (2018). Health Behaviour and Pregnancy: A Time for Change. Journal of Reproductive and Infant Psychology, 36(1), 1-3. doi: 10.1080/02646838.2018.1408965

Polit, D. F. \& Beck, C. T. (2008). Nursing Research: Generating and Assessing Evidence for Nursing Practice (8th ed). Philadelphia: Wolters Kluwer Health/Lippincott Williams \& Wilkins.

Renkert, S. \& Nutbeam, D. (2001). Opportunities to Improve Maternal Health Literacy through Antenatal Education: An Exploratory Study. Health Promotion International, 16(4), 381-388.

Tomás, C. C., Queirós, P. J. P. \& Ferreira, T. (2015). Health-promoting Behaviors: Psychometric Properties of an Assessment Tool. Texto \& Contexto-Enfermagem, 24(1), 22-29.

doi: 10.1590/0104-07072015000700014

Viboonwatthanakitt R, Pancharean S. \& Tipalonkot Y. (2007). The Relationship between Attitude toward Pregnancy and Lifestyle in Adolescent Pregnancy. Nursing Journal. 34(2): 90-97.

Walker, Z. A., \& Townsend, J. (1999). The Role of General Practice in Promoting Teenage Health: A Review of the Literature. Family Practice, 16(2), 164-172. doi: https://doi.org/10.1093/fampra/16.2.164

World Health Organization (2010). Strengthening the Health Sector Response to Adolescent and Development. Retrieved from https://www.who.int/maternal_child_adolescent/documents/cah_adh_flyer_2010_ 12_en.pdf 
Ariese Vincent A. Barca, BSN finished his Practical Nursing Course and Bachelor of Science in Nursing at Systems Plus College Foundation, Angeles City in 2016 and 2019 respectively. His research interest is in public health promotion.

Reinlynne D. Bajar, BSN, RN finished her Bachelor of Science in Nursing Degree at Systems Plus College Foundation in Angeles City in 2019. She passed her board examination last June 2019. Currently, she is connected to Angeles University Foundation Medical Center as a NICU Nurse. Her research interest is in maternal and child health nursing.

Amanda L. Caniezo, BSN finished her Bachelor of Science in Nursing Degree at Systems Plus College Foundation in Angeles City in 2019. She is currently reviewing for the upcoming board examination this June, 2020. Her research interest is in community health and wellness.

Monique Louise Dizon, BSN finished her Bachelor of Science in Nursing Degree at Systems Plus College Foundation in Angeles City in 2019. She is set to take the NCLEX-RN Examination in USA. Her research interests are health promotion and education.

Christian Jay S. Orte, PhD, RN, RM finished his Bachelor of Science in Nursing and Master of Arts in Nursing at Bataan Peninsula State University in 2009 and 2014, respectively. His Doctor of Philosophy in Nursing major in Nursing Administration was obtained at Our Lady of Fatima University in Valenzuela Campus as Meritus. He is the current research coordinator and an Associate Professor of Systems Plus College Foundation-College of Nursing and a Part-time Faculty of the Graduate School of Our Lady of Fatima University-Pampanga Campus. His research interests are in Public Health, Nursing Education, and Nursing Administration. 